\title{
Vilém Flusser e Marshall McLuhan: a Bienal de Arte de São Paulo de 1973 como ponto de contato
}

\author{
Vilém Flusser e Marshall McLuhan: the São Paulo's Art Bienal of 1973 as point \\ of contact
}

\author{
Vilém Flusser y Marshall McLuhan: la Bienal de Arte de São Paulo de 1973 \\ como punto de contacto \\ Rodrigo Miranda Barbosa \\ Universidade Federal de Pernambuco - UFPE \\ <rmbdesign@gmail.com>
}

\section{Resumo}

0 artigo propõe investigar de que maneira Vilém Flusser se engajou na discussão sobre o contexto artístico e sobre a configuração das Bienais no Brasil, e sua participação no comitê organizador da Bienal de Arte de São Paulo de 1973. Por intermédio de uma pesquisa bibliográfica, obteve-se a informação de que entre os convidados estava um grupo ligado a Marshall McLuhan para participar da Bienal. Foi analisado como se deu essa participação e apontou-se para possíveis contatos pessoais e intelectuais que fizeram com que um grupo de McLuhan fosse convidado. Concluímos que 0 artista Fred Forest pode ter sido um dos elos para essa ligação entre esses pesquisadores, mas que o encontro pessoal de fato não ocorreu.

Palavras-chave: Bienal de Arte de São Paulo. Fred Forest. Marshall McLuhan. Vilém Flusser.

\section{Abstract}

The paper proposes the investigation of how Vilém Flusser was engaged in the discussion about the artistic context and the configuration of the Bienal in Brazil, and his participation in the organizing committee of the 1973 São Paulo's Art Bienal. Through a bibliographic search, information was obtained that among the guests was a group linked to Marshall McLuhan to participate in the Bienal. It was analyzed how this participation took place and pointed to possible personal and intellectual contacts that caused a group of McLuhan to be invited. We conclude that the artist Fred Forest may have been one of the links for this connection between these researchers, but that the personal encounter did not in fact take place.

Keywords: Fred Forest. Marshall McLuhan. São Paulo's Art Bienal. Vilém Flusser.

\section{Resumen}

El artículo propone la investigación de cómo Vilém Flusser se involucró en la discusión sobre el contexto artístico y la configuración de las Bienales en Brasil, y su participación en el comité organizador de la Bienal de Arte de São Paulo de 1973. A través de la investigación bibliográfico, se obtuvo información de que entre los invitados había un grupo vinculado a Marshall McLuhan para participar en la Bienal. Se analizó cómo se llevó a cabo esta participación y se apuntó a posibles contactos personales e intelectuales que provocaron que un grupo de McLuhan fuera invitado. Concluimos que el artista Fred Forest pudo haber sido uno de los eslabones de esta conexión entre estos investigadores, pero que el encuentro personal en realidad no se produjo.

Palabras clave: Bienal de Arte de São Paulo. Fred Forest. Marshall McLuhan. Vilém Flusser. 


\section{Introdução}

Vilém Flusser, checo, radicado durante mais de 30 anos no Brasil em decorrência do nazismo, desenvolveu uma ampla bibliografia e é considerado um dos principais pensadores sobre filosofia do design, teoria literária e comunicação.

Foi colunista regular do Suplemento Literário do jornal $O$ Estado de S. Paulo, ajudou a fundar uma das principais faculdades no país (Faculdade de Comunicação e Marketing da Fundação Armando Álvares Penteado - FAAP), além de ter lecionado na Escola Superior de Cinema e na Escola de Arte Dramática (EAD) e na Universidade de São Paulo (USP).

Flusser ficou mundialmente conhecido pelo seu livro Filosofia da Caixa Preta (1985), por intermédio do qual reflete como a fotografia é o meio de comunicação que inaugura uma nova forma técnica de imagem. Apesar do seu alcance, no Brasil, recebeu pouca atenção até a sua morte por acidente, em 1991, quando voltava de carro de sua primeira palestra em Praga, sua cidade natal.

Seu primeiro período no Brasil foi de muito isolamento. Logo que chegou sofreu intensamente com a morte de sua família em Praga, em decorrência do nazismo; não sabia falar uma única palavra de português; e se fixou no Brasil trabalhando para o sogro em uma pequena indústria por 15 anos (FINGER, 2008, p. 25; HANKE, 2004, p. 60). Conseguiu estabelecer um círculo intelectual importante a partir de 1950, mas depois se viu forçado a se afastar da universidade e acabou por deixar o país na década de 1970, em um cenário de recrudescimento da ditadura militar que teve início em 1964.
Apesar disso, Flusser encontrou terreno fértil na Europa para as suas ideias. Convidado frequentemente para dar palestras nas mais variadas universidades, estabeleceu-se primeiro na Itália e depois na França. Segundo seus biógrafos, pouco tempo passava na sua casa, em razão da quantidade de viagens pela Europa.

A variedade dos textos e o contexto de produção de Flusser são considerados fatores responsáveis pela forma fragmentada e parcial como suas obras foram difundidas. Flusser escrevia em muitas línguas (checo, português, inglês, alemão e francês) e geralmente ele mesmo traduzia seus textos para estas línguas, mas quase reescrevendo-os, criando versões. Por esse motivo, certas obras só existem em uma ou outra língua; ainda, a pequena distribuição dos livros impediu-o de galgar um maior alcance (MENDES, 1999, p. 9).

Nas últimas duas décadas seu trabalho tem recebido uma crescente atenção, dados os lançamentos recentes das editoras AnnaBlume e É Realizações; bem como em razão do importante trabalho do Flusser Archive (em Berlim e em São Paulo), que tem apresentado materiais inéditos do seu pensamento. Além disso, tem-se a revista Flusser Studies como relevante aglutinador do debate em torno de Flusser.

A crescente atenção ao trabalho de Flusser também impulsionou o estabelecimento de relações entre Flusser e diversos outros autores, com o objetivo de apontar aproximações e divergências. Segundo Norval Baitello Junior (2011), na introdução do livro Filosofia da Caixa Preta, chama a atenção o fato de que, na Europa, Flusser era um autor com presença obrigatória nas disciplinas de Teorias da Comuni- 
cação, e "Flusser é um dos poucos autores que figuram em todas, absolutamente todas, ao lado de McLuhan e pouquíssimos outros" (2011, p. 8-9).

O canadense Marshall McLuhan, por seu turno, estabeleceu-se no cenário das Teorias da Comunicação justamente analisando os efeitos dos meios de comunicação na interação com a sociedade. Em razão de sua formação em literatura, ao iniciar carreira de professor nos Estados Unidos, propôs aos seus alunos a análise da publicidade a partir do mesmo rigor usualmente empregado nos estudos literários. Aos poucos suas pesquisas foram paulatinamente se direcionando para os meios de comunicação; em especial quando passou a lecionar na Universidade de Toronto e entrou em contato com um grupo de intelectuais (BUXTON, 2004), com destaque para o economista político canadense Harold Innis.

McLuhan começou a ganhar notoriedade a partir do seu livro The Gutenberg Galaxy (1962), por intermédio do qual analisou as transições entre eras comunicacionais, desde a oralidade, passando para o manuscrito até o impresso. Em seguida, com o Understanding Media (1964), colocou os recentes meios de comunicação elétricos - como a televisão - no centro do debate. A partir deste livro McLuhan atingiu uma popularidade estrondosa com seus aforismos, metáforas e frases de efeito. A título de ilustração de sua popularidade, o jornal The New York Times publicou nada mais nada menos que 17 artigos em que há menção ao trabalho de McLuhan (STRATE; WACHTEL, 2005, p. 6) em 1967. Com a mesma intensidade, entretanto, foi alvo constante de críticas e, na década seguinte, seu trabalho sofreu uma saturação midiática e intelectual, levando-o a assistir à diminuição de sua proeminência.

Contemporâneos, McLuhan e Flusser viram de perto a introdução dos meios de comunicação na sociedade e dedicaram boa parte da vida a analisar seus efeitos.

Articular o pensamento de Flusser com o do pesquisador canadense Marshall McLuhan nos parece apropriado pela importância dos dois autores para o campo do Comunicação, adotando-se como ponto de aproximação a forma como desenvolveram seus estudos ao apontarem para o lugar de destaque dos meios de comunicação para compreender a sociedade.

Alguns autores e autoras já investigaram relações entre Flusser e McLuhan, a exemplo de Kukielko e Rauch (2008), Guasque(2008), Canán (2008), Pandilovski (2016), Mersch (2008), Meulen (2010), Hanke (2012), Schaefer (2011), Weiss (2008). Além disso, há uma edição especial da revista Flusser Studies, em 2008, e, fruto de um congresso, o livro Marshall McLuhan + Vilem Flusser's Communication + Aesthetic Theories Revisited (2015). Ainda, pesquisas que se aprofundaram na participação de Flusser como um dos curadores da Bienal de 1973 (PAIVA; PEREIRA, 2015; MENDES, 2008).

Dentre seus escritos, Vilém Flusser apontou ter conhecimento sobre o trabalho de Marshall McLuhan. Entretanto, McLuhan, até onde pudemos pesquisar, não teve contato com os textos de Flusser. De outra borda, as investigações empreendidas apontam que os caminhos desses pesquisadores se aproximaram quando da realização da Bienal de Artes de São Paulo de 1973.

Flusser, além de publicar inúmeros textos sobre o contexto artístico e sobre a con- 
figuração das Bienais no Brasil, participou ativamente na curadoria da Bienal de Arte de São Paulo de 1973.

A partir do posicionamento de Flusser sobre a crise das Bienais, sua proposta comunicacional e a experimentação artística, este artigo procura analisar de que forma se deu tal aproximação. Acreditamos, assim, poder lançar luz sobre os meandros entre os trabalhos desses dois autores-chave para a pesquisa em Comunicação, que muitas vezes são percebidos como afastados, seja pela crítica de Flusser ao pensamento de McLuhan, ${ }^{1}$ seja pela busca de aproximação de Flusser com outras correntes teóricas, tais como a Teoria das Mídias Alemãs.

\section{Flusser e a Bienal de Arte de São Paulo}

Flusser e McLuhan presenciaram de perto a chegada dos meios de comunicação de massa; entretanto, Flusser, mais de perto, pôde vislumbrar a era da internet tomando forma.

Em 1963, enquanto Flusser publicava no Brasil seu primeiro livro Língua e Realidade (1963), McLuhan já vinha construindo, no Canadá, um aprofundamento na questão dos meios de comunicação com The Gutenberg Galaxy (1962) e logo em seguida publicou o seu livro de maior alcance Understanding Media (1964). No início da década de 1970, McLuhan publicou seus últimos dois livros, mas sem atingir o mesmo impacto. Em grande parte, fruto de uma saturação midiática e da crescente crítica que recebeu a partir de 1964.
Flusser, ao contrário, estava no seu último período no Brasil. Aqui, desde sua chegada na década de 1940, encontrou dificuldades para fazer parte de um círculo intelectual (FINGER, 2008, p. 25), mas aos poucos esse círculo foi tomando forma a partir da sua participação do Instituto Brasileiro de Filosofia (IBF).

Seu círculo de amizade próxima contava com o jurista e filósofo Miguel Reale, o filósofo e matemático Vicente Ferreira da Silva, o filósofo e engenheiro eletricista Milton Vargas e com artistas. Como aponta Mendes, sua relação com as artes vai se dar a partir de um "contato passivo" uma vez que era mediado pelos amigos artistas e que ele se debruçou a escrever sobre suas obras (2008, p. 150).

Seu interesse pelas artes remonta a seu primeiro livro. O artista, do ponto de vista de Flusser, é a pessoa capaz de propor soluções ao analisar o contexto a partir de pontos de vistas diferentes; algo muito próximo da posição de McLuhan em relação aos artistas como "antenas da raça", expressão que empresta de Ezra Pound.

A partir da década de 1960, a Bienal de Arte de São Paulo é ampliada e um público crescente participa das exposições pela primeira vez. Esse incremento na relevância da Bienal não fica longe dos olhares de Flusser, que, a partir de 1965, em textos publicados em jornais, começa a se dedicar à discussão sobre as Bienais e sua importância para o contexto social (PAIVA; PEREIRA, 2015). O primeiro desses textos a discutir o tema foi "Da Bienal" em 1965, e a partir daí uma série de textos se seguiram

1 Como por exemplo, a crítica ao conceito de o meio é mensagem, aldeia global, ou até mesmo denominando McLuhan de "fascistoide" (FLUSSER, 1988). 
sobre o cenário das artes no Brasil e a necessidade de estar aberto para novos modelos.

Estava instaurado no Brasil o período da ditadura militar desde 1964 e a Bienal vivia um momento de crise, a ponto de a sua edição de 1969 sofrer um duro boicote internacional dos artistas por causa das censuras do regime militar (PAIVA; PEREIRA, 2015). Além de problemas de gerenciamento, falta de estrutura e uma concentração de artistas do eixo Rio de Janeiro-São Paulo, entre outros (MENDES, 2008, p. 149).

Diante desse cenário de crise institucional, a Bienal coloca em debate sua própria estrutura assim como o seu papel no cenário brasileiro. Em uma breve apresentação para o catálogo da XI Bienal, e assinada pelo magnata, colecionador e criador da Bienal, Francisco Matarazzo Sobrinho, isso fica mais claro quando diz: "Na Bienal de São Paulo, desejamos destacar, a criatividade artística sempre encontrou liberdade, sem restrições, sem censuras" (FBSP, 1971, p. 7).

A proposta de reestruturação da Bienal começa a partir de mesas-redondas de críticos de arte juntamente à Associação Internacional de Críticos de Arte (AICA) em 1969 e em outra em 1971, na $11^{a}$ edição da Bienal (PAIVA; PEREIRA, 2015)

Dentre os tópicos em discussão, a reformulação das bienais, arte e comunicação, tema proposto por René Berger e, por último, arte e tecnologia (MENDES, 2008, p. 153). E Flusser participou de algumas dessas mesas de discussão. A posição que Flusser vinha construindo na sua série de artigos e que apresentou na mesa-redonda tinha três metas:

1) Estudar um método de fazer participar o consumidor da programação das Bienais futuras, transformando-as de "exposições" (na realidade: "imposições"), em diálogos com feedback; 2) Decidir provisoriamente se a meta da próxima Bienal é informar (apresentar máxima originalidade), ou comunicar (apresentar alguma originalidade em ambiente parcialmente redundante); 3) Instituir um grupo de comunicólogos (inclusive sociólogos, psicólogos etc.) que acompanhem constantemente os trabalhos preparatórios e executivos das Bienais futuras. (RAMIRO, 2007, p. 33).

A comunicação poderia ser um dos fatores que ajudariam a aumentar o interesse do público pela Bienal, essa foi um dos temas da segunda rodada de discussões com os críticos de arte (PAIVA; PEREIRA, 2015, p. 4)

Segundo Flusser, "Premissas: a crise da arte não é resultado de estrutura e sim de uma comunicação insuficiente com o grande público" (FLUSSER, 1972, relato I-III, p. 2 apud MENDES, 2008, p. 156). Isso estava de acordo com seus trabalhos recentes da década de 1970 (MENDES, 2008, p. 148), em que cresceu o seu interesse na interface entre arte e comunicação e experimentação artística.

A partir das reuniões de 1971, um secretariado técnico foi formado para dar conta dessa reestruturação. Este foi presidido por Francisco Matarazzo Sobrinho e integrado por Bethy Giudice, presidente da seção brasileira da Associação Internacional de Artista Plásticos; Antonio Bento, presidente da representação nacional da AICA; Mario Wilches, assistente técnico da Fundação Bienal de São Paulo; e Vilém Flusser (PAIVA; PEREIRA, 2015). 
Flusser, então, é comissionado para viajar pela Europa em busca de novos artistas e articular a participação de outras Bienais. $\mathrm{Na}$ sua atribuição, ele elabora um projeto de uma seção denominada Arte e Comunicação para a Bienal (PAIVA; PEREIRA, 2015, p. 4)

Em um dos relatos, intitulado "Proposta inicial para uma organização das futuras Bienais em base científica", Flusser justifica a importância de sua proposta:

As propostas submetidas obedecem à estrutura de árvore e são abertas. Não devem ser aceitas, nem realizadas necessariamente na sua totalidade. $\mathrm{O}$ importante é a estrutura. Mas se não for aceita a estrutura, se a Bienal continuar com estrutura fechada, terá sido perdida esta oportunidade de transformá-la em centro decisivo da vida artística, cultural e modeladora da atualidade. $\mathrm{O}$ grande valor da Bienal no momento é este: ter ela criado o potencial para a comunicação verdadeira da arte da atualidade. Se tal potencial não for utilizado, o valor da Bienal será anulado. Se for utilizado, o enorme capital de trabalho, dinheiro e inteligência investido na Bienal poderá resultar em centro modelar não apenas para a Bienal, mas para a atualidade toda. (FLUSSER apud PAIVA; PEREIRA, 2015, p.5).

O que Flusser propõe é a participação do público nas obras e uma maior interação entre público e artistas. Essa seria uma saída do modelo de discurso para o modelo de diálogo, tão presente nas obras de Flusser. Para isso, ele quer que a Bienal seja um laboratório de arte e comunicação e com a experimentação, principalmente, dos novos meios de comunicação. Para explorar a relação com os novos meios, é cogitada inclusive a transmissão do evento pela Rede Globo, primeira rede de televisão de escala nacional (MENDES, 2008, p. 157).

Segundo Mendes, Flusser demonstra em inúmeras ocasiões estar entusiasmado com o progresso de sua proposta. Em carta endereçada à Bienal em 26 de novembro de 1972:

(4.item) A ideia de transformação da Bienal em laboratório estético mundial (que estou divulgando por vários artigos em imprensa e conferências) está pegando. Ninguém doravante parece poder permitir-se o luxo de ficar por fora. (FLUSSER, 1972h, p. 2 apud MENDES, 2008, p. 158-159).

O crítico e curador francês René Berger convidou Flusser para apresentar a proposta de reestruturação da Bienal em $\mathrm{Pa}$ ris em 1972 na assembleia geral da AICA. Segundo Mendes (2008), em uma carta de 22 setembro de 1972, Flusser comentou a apresentação da proposta em Paris e, após relatar a reação negativa por parte dos presentes, passou a descrever a formação inicial de grupos de trabalho para a Bienal:

"Arquitetura e Urbanismo - Horia Damian", (b) "Animação de Imprensa" - Fred Forest, (c) "Introdução de elementos africanos na cultura" - Joseph Cornet, (d) "Grupo de comunicação de happenings" - McLuhan, (e) "Grupo de ambiente humano diário" - Institut de l'Environment, (f) "Escultura em questão" - Jean Duvig- 
nand, (g) "Organização de eventos culturais" - Radu Varia, (h) "Comportamento e gesto" - Petr Spielmann, (i) "Paredes" - Ritzi Iacobi, (j) "Folclore" - Bozo Bek, e (l) "Grupo de análise à iniciativa brasileira" - Instituto Nacional de Belas Artes (México). (FLUSSER, 1972e apud MENDES, 2008, p. 155).

Outra lista é dada por Borba Filho (2000, p.42-43), que chegou a fazer parte do comitê da seção de Flusser. Os participantes convidados por Flusser para a Bienal de 1973 foram:

Jean Oth e Gerald Minkof, ambos videoartistas suíços; Hervé Fisher e Fred Forest, franceses, sócios em um Coletif d'Art Sociologique, junto com Jean Thenot e mantenedores da École de Sociologie Interrogative, praticantes da Arte Sociológica; e Horia Damien escultor e criador de objetos de arte, refugiado da cortina de ferro, que enviou seu procurador Radu Varia que funcionava, também, como uma espécie de legado do Flusser que ficou pela Europa.

Também foi convidado um norte-americano trazido pela curadora Regina Cornwell e um "grupo canadense ligado" a McLuhan. Não fica claro como surgiu na lista o "'Grupo de comunicação de happenings' - McLuhan”.

A escolha dos convidados demonstrava a preocupação de Flusser com a experimentação e a ideia de um laboratório, além da incorporação de videoartistas e das novas tecnologias de comunicação (BORBA FILHO, 2000, p. 42-43).
Escrito por Márcio Sampaio, o artigo intitulado "Matarazzo quer Bienal para as massas” (1973) discorre sobre um press release recebido da Fundação Bienal de São Paulo explicando as propostas da Bienal de 1973: de interação com o público e da importância da comunicação.

Por esse motivo a XII Bienal de São Paulo quer dar ênfase especial à comunicação, criando motivações novas, estimulando e acionando as áreas dos artistas, críticos, estudiosos das questões artísticas, teóricos da comunicação, canais de divulgação, setores culturais, manipuladores da mass-media e o grande público. Haverá, portanto, um esforço conjunto de todos os setores que, somados, assegurarão à manifestação de São Paulo uma presença viva, uma movimentação ativa, um diálogo efetivo capaz de assegurar uma participação ativa do público. (1973, p. 2).

Apesar do planejamento do comitê e da dedicação de Flusser, aos poucos surgiram inúmeros problemas até a chegada do evento.

\section{A Bienal não sai como planejado}

Quando participou das reuniões da AICA em Paris a pedido de René Berger em 1972, Flusser já não estava mais morando no Brasil. Sua interação com a comissão da Bienal deu-se principalmente por cartas. E ao longo de 1972-1973, a proposta de Flusser começou a perder força diante de uma série de acontecimentos que foram criando uma tensão, pelo menos desde setembro de 1972 (MENDES, 2008, p. 159). 
Entre elas, havia uma carta endereçada para Francisco Matarazzo Sobrinho pedindo mais dez mil dólares para continuar realizando seu trabalho da Europa de obter sugestões para a Bienal e procurar artistas para participarem da Bienal de 1973 (PAIVA; PEREIRA, 2015, p. 5-6). Matarazzo Sobrinho enviou um ultimato para Flusser dizendo que os custos não eram para suas atividades pessoais e um valor final de dois mil dólares foi enviado (MENDES, 2009, p. 159).

Quando a Bienal aconteceu, em 1973, Flusser não estava presente. A mudança proposta para a Bienal teve como efeito a recusa de $90 \%$ dos artistas brasileiros, que acabaram criando uma bienal paralela (AMARANTE, 1989, p. 214). E a falta de uma curadoria transformou o cenário em desorganização.

Dentro da proposta de interação com o público (PAIVA; PEREIRA, 2015, p. 6) inicialmente planejada por Flusser, apenas Forest e "Eric McLuhan" de fato apresentam suas obras na Bienal (MENDES, 2008, p. 162).

Leonor Amarante (1989) descreve a participação e a obra de "Eric McLuhan" apresentada na Bienal da seguinte maneira:

Na década de 1960, o canadense Marshall McLuhan, polêmico teórico da comunicação de massa, profetizou que o planeta se transformaria, em pouco tempo, numa aldeia global. Anos depois, seu filho, Eric Marshall McLuhan, veio a São Paulo conferir a Bienal, mostra que resumia o mapa-múndi das artes plásticas numa vitrine única de 38 mil metros quadrados. Professor de Comunicações na Universidade de Toronto, Marshall e sua equipe, formada de engenheiros de som, cineasta, desig- ner e artistas plásticos, apresentaram na Bienal o projeto Mostrando São Paulo para São Paulo. Novamente sem uma firme coordenação geral e com a habitual ausência de um curador capaz de amarrar os vários segmentos, muitos participantes foram surpreendidos às vésperas da inauguração. A equipe canadense, por exemplo, não encontrou nada pronto, embora tivesse seguido à risca as determinações dos organizadores. Seus integrantes garantiram que em junho enviaram a lista do material desejado, o projeto do estande e o local onde deveriam fazer suas experiências. Marshall se recordou: 'Mais tarde, quando chegamos aqui, o estande estava sem teto, sem pintura, não havia mesas e nem cadeiras. A Bienal começou e o público nos encontrou em plena montagem'. A proposta dos canadenses se dividiu em três partes. Na primeira, dois espelhos numa sala fechada. A pessoa se via como ela era e mais nada. A segunda consistia em vendar os olhos do espectador, fazendo com que percebesse os sons ambientes e, em seguida, os diferentes ruídos da cidade gravados em fita. Depois de 20 minutos de som, na terceira parte, os participantes iam para uma sala ao lado e transmitiam de forma sensível ou visual tudo o que sentiram. Os canadenses ainda propuseram uma experiência mais ousada e que não pôde ser concretizada: 0 público deveria permanecer de 12 a 24 horas com os olhos vendados. (AMARANTE, 1989, p. 222-223).

Não ficaram muito claras as razões que fizeram com que os autores (MENDES, 
2008, p. 162; PAIVA; PEREIRA, 2015, p. 6) chamassem a atenção para Eric McLuhan de forma isolada nas propostas e apresentações realizadas na Bienal. É curioso o fato de que, no catálogo da Bienal de 1973, o nome de Eric McLuhan (filho de Marshall McLuhan) não aparece, mas apenas o de Derrick de Kerckhove, então assistente de McLuhan. No futuro, este veio a ser o novo diretor do Marshall McLuhan Program in Culture and Technology na Universidade de Toronto, na retomada do centro após a morte de McLuhan. Apesar de constar no catálogo oficial da Bienal, Kerckhove não aparece nas descrições feitas por Mendes (2008) e Paiva e Pereira (2015), apenas menciona-se Eric McLuhan. Ademais, o nome de Flusser aparece com erro de grafia no catálogo da Bienal, constando como "Willém Flusser" (1973, p. 274).

Outro caso interessante é que não sabemos quem Amarante (1989) está descrevendo como "os canadenses" na sua descrição da obra. Ele está fazendo referência a Eric McLuhan e Derrick de Kerckhove ou a Eric McLuhan e Marshall McLuhan? Na descrição feita por ele (1989), até o nome de Eric apresenta erro de grafia, pois o correto é Eric McLuhan e não "Eric Marshall McLuhan" (o erro que persiste em Mendes, 2008, p. 161-162).

O encontro entre Eric McLuhan e Derrick de Kerckhove com Flusser não aconteceu. Flusser ficou afastado da Bienal até 1981 quando veio ao Brasil como palestrante (PAIVA; PEREIRA, 2015, p. 9).

Ainda assim, alguns movimentos podem demonstrar como Flusser aproximou-se do grupo de McLuhan. Um desses movimentos, acreditamos, deu-se no encontro em Paris, em 1972. Nele, Flusser conheceu o artista Fred Forest por intermédio do teórico da informação Abraham Moles (SCHWENDENER, 2018, p. 22). Fred Forest foi um importante ponto de contato entre Flusser e McLuhan.

\section{Fred Forest}

Fred Forest foi um pioneiro na videoarte na França e transformou-se em grande amigo e parceiro de Flusser ao longo dos anos. Na Bienal, a convite de Flusser, apresentou uma obra da série Space-Media, que já havia executado anteriormente em Paris em 1972.

Uma das suas ações do projeto Space- Media consistia em obter espaços em branco de jornais de grande circulação de São Paulo e do Rio de Janeiro para o público desenhar ou escrever mensagens.

Em outra ação emblemática e executada na Bienal em São Paulo, denominada The City Invaded by Blank Space, Forest contratou pessoas para carregarem placas de protesto em branco no meio das ruas para então contestar a censura à liberdade de expressão imposta pelo governo militar. Forest acabou sendo preso pelo Departamento de Ordem Política e Social (DOPS) e a embaixada da França, juntamente com a organização da Bienal, teve que intervir para conseguir a liberação do artista (ARANTES, 2009, p. 6).

Já dentro da Bienal, Forest instalou vários telefones para os quais qualquer pessoa poderia ligar e deixar mensagens, que eram então ouvidas através dos alto-falantes instalados pela Bienal (SCHWENDENER, 2018, p. 25).

Esse tipo de experimentação era um dos objetivos de Flusser com o convite feito a 
Forest. O próprio Flusser participou de alguns vídeos de Forest, dentre eles o mais interessante é Gestos do Professor (1973). ${ }^{2}$ Nele, Flusser aparece apresentando a sua teoria dos gestos enquanto Forest está gravando em vídeo toda a explicação e a câmera vai se aproximando e sendo guiada pelos gestos feitos por Flusser. Flusser depois escreveu um ensaio sobre a experiência explicando que o fato de estar sendo filmado mudava consideravelmente a forma dos seus gestos. Nessa construção, Flusser percebeu que não era totalmente livre, que ele tinha que se adaptar à câmera que estava filmando.

\begin{abstract}
A câmera tornava-se, como que espontaneamente, uma ferramenta epistemológica, um instrumento para compreender. Mas este instrumento tinha um efeito direto sobre a "coisa a ser compreendida": sobre o meu discurso. (FLUSSER, 2009, p. 174).

Nesse exemplo, o método seguido por Forest é o da observação de um fenômeno social (neste caso: eu mesmo em relação a Forest) aceitando, cada vez mais conscientemente, o fato que esta observação muda tanto o fenômeno observado quanto o observador do fenômeno. (FLUSSER, 2009, p. 175).
\end{abstract}

Essa experiência de Flusser com Forest depois serviu de base para a coleção de ensaios publicada como Gesten (1991), de Flusser. Como aponta Mendes (2008, p. 165):
A descoberta do vídeo como meio de realização, as proposições para as Bienais de Paris e São Paulo e o recurso da paraficção estabelecem um campo no qual Flusser propõe-se a explorar novas linguagens para a filosofia contemporânea, novas mediações.

Forest ajudou na inspiração de Flusser para a exploração dos novos meios de comunicação. E como aponta Gary Genosko, o projeto de Forest realizado em Paris e depois no Brasil, denominado Space-Media, foi "Inspired by McLuhan's focus on the medium" (1999, p. 86). ${ }^{3}$

Forest conhecia Marshall McLuhan e Derrick de Kerckhove. Inclusive, Forest foi o cofundador do projeto artístico denominado "Collectif d'Art Sociologique" (Coletivo de Arte Sociológica) com Mario Costa e Derrick de Kerckhove. Realizando experimentações, "Using documentary video, feedback from participants, publications, and collaborations with academic sociologists, they created an 'aesthetic form of sociology" "4 (SCHWENDENER, 2018, p. 25).

Segundo Derrick de Kerckhove, ele e Marshall McLuhan conheceram Forest em 1972. Pouco tempo depois, McLuhan escreveu um pequeno prefácio para uma prática artística sobre uma instalação feita por Forest, que utilizava telefones fixos.

Neste texto, McLuhan (1973) congratula Forest por suas tentativas de revelar os mistérios do telefone. Denomina o telefone

\footnotetext{
2 Apesar da referência do Arquivo Flusser de São Paulo informar o ano 1973, 0 artista Fred Forest diz que o material foi produzido entre 1972 1974. Ver em http://www.fredforest.org/book/html/en/actions/03_en.htm\#text 3 Tradução livre: "Inspirado pelo foco de McLuhan nos media".

4 Tradução livre: "Utilizando documentação em vídeo, feedback de participantes, publicações e colaborações com acadêmicos sociólogos, eles criaram uma espécie de 'sociologia estética'".
} 
como o meio de comunicação mais ignorado e que apenas os adolescentes compreendem. McLuhan então passa a analisar o telefone enquanto meio de comunicação e a relação de presença que ele cria. Ele cita que as crianças não dizem que "o tio Fred está ligando” (1973, tradução nossa) elas dizem "o tio Fred está aqui”. Os mais letrados têm horror ao telefone, pois é uma intrusão de suas vidas privadas enquanto os jovens agem com naturalidade. Outro ponto que ele chama a atenção é que, quando instalaram linhas telefônicas para os esquimós no Canadá, eles não aceitaram o telefone enquanto ligações de um para um, eles queriam que todos participarem das ligações telefônicas, ligações coletivas, as denominadas "party-line".

Forest tinha interesse no trabalho de McLuhan ao ponto de ter suas propostas artísticas relacionadas com conceitos deste último. Michael F. Leruth, que dedica um livro à análise da obra e biografia de Forest, descreve o projeto "Aesthetics of Communication" da seguinte forma:

[...] his practice of the Aesthetics of Communication often entailed the creation of his own special parallel circuits of communication comprised of diferent media combinations, and it attached no more than secondary importance to any messages that might actually be conveyed. As Marshall McLuhan put it, the medium is the message. (LERUTH, 2017, p. 98). ${ }^{5}$

Essa rede de relações de Fred Forest até Marshall McLuhan e Derrick de Kerckho- ve pode ter tido influência no interesse de Flusser no grupo canadense para a Bienal em 1973.

Segundo contato com Derrick de Kerckhove (2020), o convite para participar da Bienal em 1973 partiu de Radu Varia e foi endereçado a ele. Kerckhove, então, trouxe consigo Eric McLuhan, Jacques Goudzousian (engenheiro de som) e algumas pessoas ligadas à TVOntario para realizarem a instalação das experiências sensoriais na Bienal. Radu Varia foi outro contato importante nessa triangulação com o grupo de McLuhan, pois ele era justamente o contato de Flusser na Europa, como aponta carta endereçada para o diretor da Bienal de São Paulo (FLUSSER, 1972g, apud MENDES, 2008, p. 156)

O fato é que Flusser durante toda a sua vida estabeleceu aproximações e divergências com a obra de McLuhan. Dentre elas podemos destacar as críticas ao conceito de aldeia global (2007, p. 274) e o meio é mensagem (2007, p. 272); mas, ao mesmo, tempo aproximações: quando Flusser reconheceu que McLuhan era uma das principais figuras que estavam pensando nos mesmos problemas que ele (1988).

\section{Considerações finais}

$\mathrm{O}$ presente artigo procurou explorar de que forma Vilém Flusser se envolveu com o cenário das artes e das Bienais no mundo; e como ele se envolveu com a Bienal de Arte de São Paulo de 1973, bem como seu quase contato com Marshall McLuhan durante essa realização.

5 Tradução livre: "[...] sua prática da Estética da Comunicação frequentemente envolvia a criação de seus próprios circuitos paralelos especiais de comunicação composta por diferentes mídias combinações, e não conferiu mais do que a importância secundária para quaisquer mensagens que pudessem realmente ser transmitidas. Como Marshall McLuhan colocou, o meio é a mensagem". 
O contato com Fred Forest pode ter sido uma das influências no interesse de Flusser pela participação do grupo de McLuhan (através da figura de Derrick de Kerckhove) na Bienal de 1973, mas não o único, existem inúmeros outros contatos possíveis que podem ter acontecido.

Dentre os contatos possíveis, podemos destacar o teórico da informação e amigo pessoal Abraham Moles em Paris, em 1972. Foi Moles quem ajudou a publicar o primeiro livro em francês de Flusser: $L a$ Force du Quotidien (1973), uma coleção de pequenos ensaios dedicados a objetos do dia a dia. E justamente no prefácio dessa obra, escrito por Moles, ele compara o texto de Flusser com o livro Understanding $\mathrm{Me}$ dia (1964) de McLuhan (SCHWENDENER, 2018, p. 22).

Outro contato possível é do crítico e curador francês René Berger, que convidou Flusser para participar de mesa de discussão em Paris. Ele é considerado por Genosko um "less well-known reader of McLu- han"“ (1999 p. 72), além disso é possível encontrar foto na internet de McLuhan e Berger juntos.

No Brasil, uma das pessoas que compunha o círculo de amizade de Flusser era o poeta Haroldo de Campos, cuja poesia Flusser traduziu para o Alemão (SCHWENDENER, 2018, p. 22). Haroldo de Campos, juntamente a seu irmão Augusto de Campos e Décio Pignatari, faziam parte do grupo que obteve reconhecimento internacional com o movimento concretista. Décio Pignatari, não por acaso, foi tradutor do livro Understanding Media, em 1969, para o português. Não seria estranho pensar que em algum momento estas ligações tenham ficado aparentes para Flusser.

Estes são apenas alguns contatos que podem ter aproximado Flusser do pensamento e do próprio Marshall McLuhan. Como dissemos alhures, dificilmente algum pensador dos meios de comunicação, a partir da década de 1960, poderia ter escapado da notoriedade de McLuhan.

\section{Referências bibliográficas}

AMARANTE, Leonor. As Bienais de São Paulo: 1951 a 1987. São Paulo: Projeto, 1989.

ARANTES, Priscila. Mídia, gestos e sociedade diálogos entre Vilém Flusser e Fred Forest. Flusser Studies 08, 2009.

BAITELLO JUNIOR, Norval. O aparelho e o bote. Filosofia da Caixa preta quase três décadas depois. In: FLUSSER, V. Filosofia da Caixa Preta. São Paulo: Annablume, 2011.

BORBA FILHO, Gabriel. Presença de Flusser. In: BERNARDO, G.; MENDES, R. (orgs.). Vilém Flusser no Brasil. Rio de Janeiro: Relume Dumará, 2000. p. 33-44.

BUXTON, W. J. The "Values" Discussion Group at the University of Toronto, February-May 1949. Canadian Journal of Communication, [S.l.], v. 29, n. 2, feb. 2004.

CANÁN, A. J. L. Carrillo. McLuhan, Flusser and the Mediatic Approach to Mind. Flusser Studies 06 - May 2008. 
DE KERCKHOVE, Derrick. Participation at São Paulo's Art Bienal [mensagem pessoal]. Mensagem recebida por <rmbdesign@gmail.com> em 4 mai. 2020

FINGER, A. As redes de Flusser. In: BERNARDO, G.; FINGER, A.; GULDIN, R. Vilém Flusser: uma introdução. São Paulo: Annablume, 2008. p.13-32.

FLUSSER, Vilém. "Da Bienal”. O Estado de S. Paulo, São Paulo, 4 set. 1965, Suplemento Literário, 6, p. 40

FLUSSER, Vilém. La force du quotidien. Paris: Mame, 1973.

FLUSSER, Vilém. Filosofia da caixa preta. São Paulo: Hucitec, 1985. 92 p.

FLUSSER, Vilém. "On writing, complexity and the technical revolutions" [Entrevista concedida a Miklós Peternák] Osnabrück, European Media Art Festival, Setembro de 1988. Disponível em: https://www.youtube.com/watch?v=8rtZXpMUlS8. Acesso em: 6 maio 2020.

FLUSSER, Vilém. Gesten: Versuch einer Phänomenologie. Bollmann Verlag: 1991.

FLUSSER, Vilém. Kommunikologie. Frankfurt/M: Fischer, 2007.

FLUSSER, Vilém. "Fred Forest ou a destruição dos pontos de vista estabelecidos". ARS, São Paulo, v. 7, n. 13, p. 172-179, Junho 2009.

FOREST, Forest. Gestures of the Professor / Os Gestos do Professor. 1973. Disponível em: https://www.youtube.com/watch?v=qhFH7_cUgFc. Acesso em: 6 maio 2020.

FUNDAÇÃO BIENAL DE SÃO PAULO (FBSP). XI Bienal: setembro/novembro 1971. São Paulo: FBSP. (catálogo de evento), 1971.

GENOSKO, Gary. McLuhan and Baudrillard: Masters of Implosion. London: Routledge, 1999.

GUASQUE, Y. A cidade como um medium em McLuhan e Flusser / The City as a Medium in McLuhan and Flusser. Flusser Studies 06 - May 2008.

HANKE, B. Vilém Flusser's Digital Galaxy. International Journal of Communication 6, Book Review 25-35. 2012.

HANKE, Michael. A Comunicologia segundo Vilém Flusser. Galáxia. [S.1.], n. 7, fev. 2004.

KOHUT, T.; PANDILOVSKI, M. Marshall McLuhan and Vilém Flusser's communication and aesthetic theories revisited. Winnipeg: Video Pool Media Arts Centre, 2015.

LERUTH, Michael F. Fred Forest's Utopia: Media Art and Activism. Cambridge: MIT Press, 2017.

McLUHAN, M. The Gutenberg galaxy: The making of typographic man. Toronto: University of Toronto Press, 1962.

McLUHAN, M. Understanding Media: The Extensions of Man. London: Routledge \& Kegan Paul, 1964. 
McLUHAN, M. Uncle Fred is here! Fred Forest and the telephone. 1973. Disponível em: https://www.academia.edu/38437562/Marshall_McLuhan_and_FF.pdf. Acesso em: 6 maio de 2020 .

MENDES, Ricardo. Bienal de São Paulo 1973 - Flusser Como Curador: Uma experiência inclusa. Revista de Comunicação, Cultura e Teoria da Mídia. São Paulo, março/2008 n. 11. p.147-171.

MERSCH, D. Kritik des Medienteleologismus. McLuhan, Flusser und Hegel, in: Derrick de Kerckhove, Martina Leeker, Kerstin Schmidt (Hg.), McLuhan neu lesen. Kritische Analysen zu Medien und Kultur im 21. Jahrhundert, Bielefeld (transcript) 2008, S. 196-209.

MEULEN, Sjoukje. Between Benjamin and McLuhan: Vilém Flusser's Media Theory. New German Critique, v. 37, p. 180-207, 2010.

PANDILOVSKI, M.. What lies behind modern technology? The approaches of Marshall McLuhan and Vilém Flusser. Glimpse, v. 17, p.77-85, 2016.

RAMIRO, Mario. Salto para um mundo cheio de deuses. ARS (São Paulo), São Paulo, v. 5, n. 10, p. 32-37, 2007.

SAMPAIO, Márcio. Matarazzo quer Bienal para as massas. MINAS GERAIS. Suplemento Literário. Belo Horizonte. v. 8, n. 334, p. 2, jan. 1973. Disponível em: http://www.letras. ufmg.br/websuplit/arquivos.php?a=1973\&c=08033401197302

SCHAEFER, P. Vilém Flusser's philosophy of new media history. New Media \& Society, v. 13, n. 8, p. 1389-1395, 2011.

SCHWENDENER, M. Vilém Flusser's Seventies: Phenomenology, Television, Cybernetics, and Video Art. Afterimage, [s. 1.], v. 45, n. 5, p. 22-28, 2018. DOI 10.1525/aft.2018.45.5.22. Disponível em: http://search.ebscohost.com/login.aspx?direct=true\&site $=e d s-l i v e \& d b=a 9 h$ $\& A N=133540561 \&$ custid $=$ s6224580. Acesso em: 6 maio 2020.

WEISS, S. L. Human Consciousness and the Construct of Meaning in the Communication Theories of Marshall McLuhan and Vilém Flusser. Flusser Studies 06 - May 2008.

Data da submissão: 28/05/2020

Data do aceite: 03/07/2020

Dados do autor:

Rodrigo Miranda Barbosa

https://orcid.org/0000-0002-0053-3515

http://lattes.cnpq.br/6498132660066720

Doutor em Comunicação. Professor do curso de Comunicação Social da UFPE - Centro Acadêmico do Agreste, Caruaru - PE

rmbdesign@gmail.com 